\title{
Fire Safety in Extraterrestrial Environments
}

Robert Friedman

Lewis Research Center, Cleveland, Ohio

Prepared for the

Sixth International Conference and Exposition on Engineering, Construction, and Operations in Space sponsored by ASCE, NASA, and AAS

Albuquerque, New Mexico, April 26-30, 1998

National Aeronautics and

Space Administration

Lewis Research Center

May 1998 
Available from

NASA Center for Aerospace Information 7121 Standard Drive

Hanover, MD 21076

Price Code: A03
National Technical Information Service 5287 Port Royal Road Springfield, VA 22100 Price Code: $\mathrm{A} 03$ 


\title{
FIRE SAFETY IN EXTRATERRESTRIAL ENVIRONMENTS
}

\author{
Robert Friedman \\ National Aeronautics and Space Administration \\ Lewis Research Center \\ Cleveland, Ohio 44135
}

\begin{abstract}
Despite rigorous fire-safety policies and practices, fire incidents are possible during lunar and Martian missions. Fire behavior and hence preventive and responsive safety actions in the missions are strongly influenced by the low-gravity environments in flight and on the planetary surfaces. This paper reviews the understanding and key issues of fire safety in the missions, stressing flame spread, fire detection, suppression, and combustion performance of propellants produced from Martian resources.

\section{INTRODUCTION}

Human-crew space operations are inherently dangerous. Among the obvious threats of radiation exposure, atmospheric-pressure loss, meteoroid penetration, and the like, fire is perhaps the most easily recognized and understood. In the closed environment of a spacecraft or extraterrestrial base, with no avenue for escape, a fire is greatly to be feared. Yet, the experience in human-crew space missions to date has been exemplary. Even minor incidents have been rare, and only one fire-on Mir in February 1997-required active suppression (Ross, 1997).

Extraterrestrial missions will offer new challenges to fire safety, however. Fire-precursor breakdowns are likely to occur at times in the very long durations of the proposed flight and surface operations. Furthermore, safety technology must be tailored to respond to the unusual fire characteristics in low-gravity environments (Friedman, 1992-1993).

This paper reviews the understandings and issues in fire safety for the extraterrestrial missions to the Moon and Mars. Some of the findings are based on the conclusions of a working group on fire safety, chaired by the author, which was part of the August 1997 NASA Workshop on Research for Space Operations.
\end{abstract}

\section{DESCRIPTION OF EXTRATERRESTRIAL MISSIONS}

Unlike the Apollo missions, which were designed for limited-duration lunar surface explorations, the planned extraterrestrial missions aim to establish long-term, human-occupied bases on the Moon and Mars. These bases will support diverse operations, such as exploration, planetary science, and propellant manufacture.

Martian missions command great interest in the public and aerospace community, and they present a formidable challenge to technology and human support. A typical mission proposal, conservative in cost and propellant usage, requires at least 180 days in transit to Mars (Zubrin and Weaver, 1995). Preceding the human-crew venture, unmanned flights to the surface of Mars will land and assemble complete facilities, including surface rovers, power plants, inflatable habitation structures, raw materials for surface processing, and a return vehicle (Ross, 1997). The crew will likely remain at the Martian base for over 500 days before the planetary alignment is favorable for the return to earth. The return vehicle will be powered by methane and oxygen propellants, which are to be manufactured on Mars during the surface operations. It is possible to overlap missions by launching unmanned supply and assembly flights for the next mission while the first crew is still occupying the Mars surface base.

Typical lunar-mission proposals are, in principle, similar to those for Mars. Surface bases are exposed to greater variation in ambient temperatures and heavier flux of particles and radiation than on Mars and thus need better insulation from the environment. There is no source of atmospheric gases for the manufacture of propellants and oxidants on the Moon. On the other hand, transit times to the Moon are of the order of a few days rather than months, and resupply and return missions can be maintained on a regular, short-term basis. 


\section{THE REDUCED-GRAVITY ENVIRONMENTS}

A practical, realistic mission to the Moon or Mars must assume, for the most part, unpowered flight. Over this free-fall path, the vehicle and its contents are subject to near-zero residual gravitational acceleration-in the range, perhaps, of $10^{-4}$ to $10^{-6} \mathrm{~g}$, where $\mathrm{g}$ is the earth sea-level acceleration (normal gravity) of $9.8 \mathrm{~m} / \mathrm{s}^{2}$. This near-zero acceleration is commonly termed microgravity.

The microgravity environment of earth-orbiting spacecraft has proven to be beneficial in simplifying and aiding fundamental research in combustion, fluids, materials, and biotechnology. On the other hand, the microgravity environment contributes to the extreme difficulty of many routine human and mechanical operations in space.

The impact of microgravity on fire behavior is substantial. Fires generate large density gradients, which produce upward buoyant flows under the influence of terrestrial gravity. In microgravity, buoyant forces and flows are reduced or eliminated, greatly modifying heat and mass transport rates and, in turn, fire characteristics and control. The consequence may be either an increase or decrease in fire initiation and spread, depending on the particular scenario. Thus, the relationship of microgravity fire hazards to those in normal gravity is, in general, difficult to assess (Ross, 1996).

Operations on the surfaces of the Moon and Mars are subject to gravitational accelerations that are fractions of normal gravity, about $0.38 \mathrm{~g}$ on Mars and $0.16 \mathrm{~g}$ on the Moon (table I). These are termed partial gravity in this paper. Fires are also substantially influenced by partial gravity. In fact, fire characteristics appear to be unique in some partial-gravity cases, differing even from those in microgravity (Ross, 1997).

TABLE 1. COMPARISON OF PLANETARY SURFACE ENVIRONMENTS

\begin{tabular}{|l|l|l|l|}
\hline \multicolumn{1}{|c|}{ Property } & \multicolumn{1}{|c|}{ Earth } & \multicolumn{1}{|c|}{ Moon } & \multicolumn{1}{c|}{ Mars } \\
\hline Temperature Range, K & $233-328$ & $102-384$ & $130-300$ \\
Daily Cycles per Earth Year & 365 & 13 & 356 \\
Atmospheric Pressure Range, kPa & 101 Mean & $10^{-13}-10^{-9}$ & $0.60-1.5$ \\
Atmospheric Composition, \% & & & \\
$\mathrm{N}_{2}$ & 78.1 & - & 2.7 \\
$\mathrm{O}_{2}$ & 20.9 & - & 0.13 \\
$\mathrm{Ar}$ & 0.93 & - & 1.6 \\
$\mathrm{CO}$ & 0.03 & - & 95.3 \\
$\mathrm{Gravitational} \mathrm{Acceleration,}$ & & & \\
$\mathrm{m} / \mathrm{s}^{2}$ & 9.807 & 1.62 & 3.73 \\
$\mathrm{Relative}$ to Earth & 1 & 0.165 & 0.380 \\
\hline
\end{tabular}

\section{SPACECRAFT FIRE-SAFETY STRATEGIES}

Spacecraft fire-safety practices are founded foremost on fire prevention. This implies the near-elimination of one of the elements of the familiar fire triangle, namely, fuel, ignition, and oxygen. Fuel is minimized by limiting materials and components to those meeting acceptability criteria based on resistance to fire spread. Ignition is minimized by conservative wire-current ratings, electrical bonding and grounding, high-safety-factor pressure-vessel ratings, and so on (Friedman, 1996).

Clearly, fire-prevention policies cannot achieve their goals with absolute assurance. Many flammable materials must be accepted for service on spacecraft, due to a lack of substitutes; but these can be regulated in quantity, spacing, and storage requirements. The long-duration exposure in flight and on surface bases in extraterrestrial missions will provide greater opportunities for fire risks, with possible occurrences of mechanical and electrical breakdowns, sensor and alarm-system failures, suppressant leakage, material aging, and human errors. Furthermore, the long missions require a greater level of housekeeping and support activities, which add fire dangers in cooking, laundry, and trash accumulation.

The third element of the fire triangle, oxygen, is obviously present in any life-supporting atmosphere. Flammability of materials increases with atmospheric oxygen: few materials are truly fire resistant at 40 percent or greater oxygen concentrations. Yet, it is costly in terms of mass and volume to carry nitrogen on long-duration flights merely for atmospheric dilution. First-order proposals for Martian missions assume that atmospheres in the spacecraft and surface bases are either pure oxygen or enriched-oxygen mixtures (Personal comments, D.I. Kaplan, NASA Johnson, 1997). 


\title{
FIRE-SAFETY ISSUES
}

\author{
Fire Propagation
}

Spacecraft materials are evaluated for resistance to upward fire spread in standard tests on the ground at normal gravity. This, of course, is an expediency; but the testing is justified by the view that the buoyancyaided combustion represents a "worst case," as compared to expected fire behavior in microgravity.

As noted, the relationship of the microgravity to normal-gravity fire hazard is difficult to generalize, but some microgravity-combustion research results are now available to assess these differences. A major contributor to fire knowledge has been the data and models obtained in a series of ten (to date) separate Shuttle tests, investigating sheet-material flammability (Ramachandra, et al., 1995). Flames propagate at uniform rates over thin-paper fuels in quiescent, oxygen-enriched microgravity atmospheres. On the other hand, flames over thicker plastic fuels propagate nonuniformly, decreasing in rate with time. (The two-dimensional model predicts eventual extinction.) In all cases, however, microgravity flame spread is strongly enhanced by forced ventilation (obviously present in human-crew spacecraft and bases). Smoldering propagation, for example, is maintained in polyurethane foams by velocities as low as $1 \mathrm{~mm} / \mathrm{s}$ through the sample (Walther, et al., 1997).

For partial-gravity environments, limited data are available on flammability and flame propagation over thin-paper fuels. Figure 1 illustrates published data on flame-spread rates from airplane and other tests conducted over a range of gravitational accelerations (Sacksteder and T'ien, 1993). The interesting result is that the maximum flame-spread rate occurs near the gravity level of the Martian surface. The flame-spread rate is lower near the gravity of the lunar surface, but it still exceeds the rate at normal gravity $(\mathrm{g}=1)$. A flammability map of the minimum atmospheric-oxygen concentration for flame spread as a function of gravity is shown in figure 2 . These data show that flammability increases as gravity decreases from terrestrial values into the partial-gravity range. Extrapolation suggests that flammability range would be greatest as microgravity is approached. Results of modeling studies, however, predict that the flammability range is a maximum at partial gravity and diminishes in the microgravity range (Sacksteder and T"ien, 1994). Thus, in some scenarios, partial-gravity flammability may represent a worst case compared to that under microgravity or normal gravity. In any event, partial-gravity flammability does not appear to be predictable merely by interpolation between normal-gravity and microgravity experience.

\section{Fire Detection}

Of necessity, smoke detectors for spacecraft are derived from proven terrestrial designs, modified to aid sampling and to reduce mass and power consumption (Martin and DaLee 1993, McKinnie, 1997). In current service, spacecraft smoke detectors use the principles of ionization-current interruption (Shuttle) or light-beam obscuration and scattering (International Space Station, ISS). Long-term reliability, compact size, and reduced energy consumption, rather than performance superiority, dictate the selection of the ISS light-beam model.

Early-warning fire detection is based on the sensing of fire signatures, or the abnormalities that indicate fire or fire precursors. Typical signatures are smoke, gaseous products, heat, radiation, and pressure rise. Firesignature characteristics can be affected by gravity level. An elementary research example is that of a candle burning in a quiescent microgravity environment, which produces no smoke. The same candle burning with a low-rate, added air flow produces considerable smoke (Dietrich, et al., 1994). Smoke collected from burning wire insulations, turbulent gas jets, and other flames indicates that, in many cases, smoke constituents tend to agglomerate and form large particles in microgravity, increasing the average size and size distribution (Ku, et al., 1995). Other low-gravity influences on fire signatures include altered flame radiation and gaseous emissions (Friedman, 1996). 


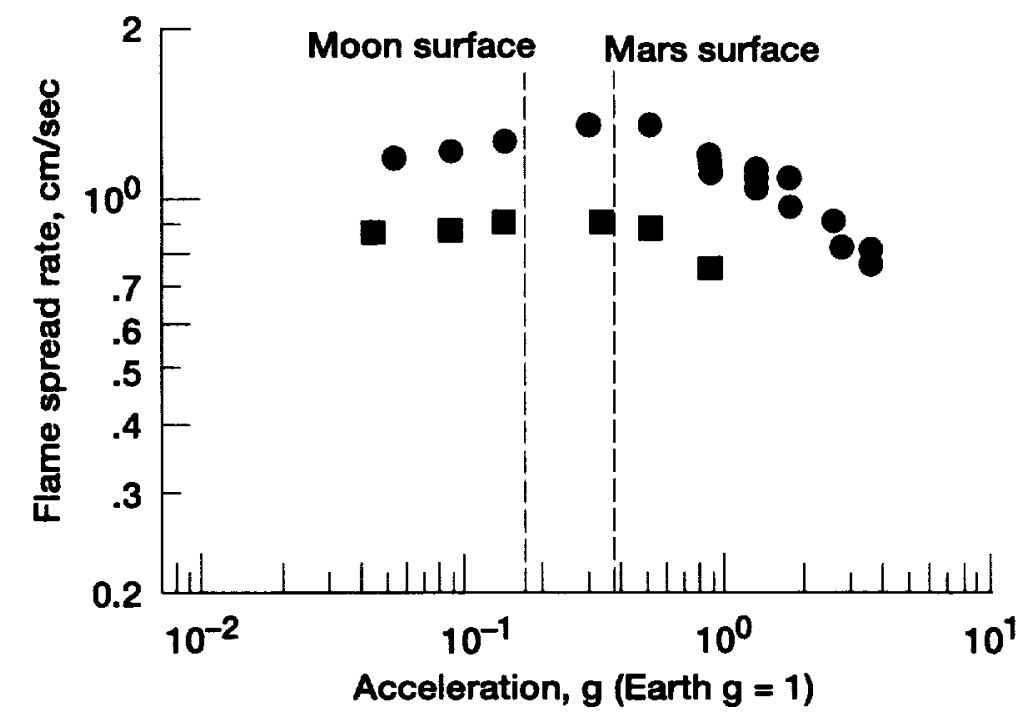

Figure 1. Experimental downward flame-spread rates for thin-paper fuels at $101 \mathrm{kPa}$ total pressure and a range of gravitational accelerations. Circles are $21 \%$ oxygen; squares are $18 \%$ oxygen.

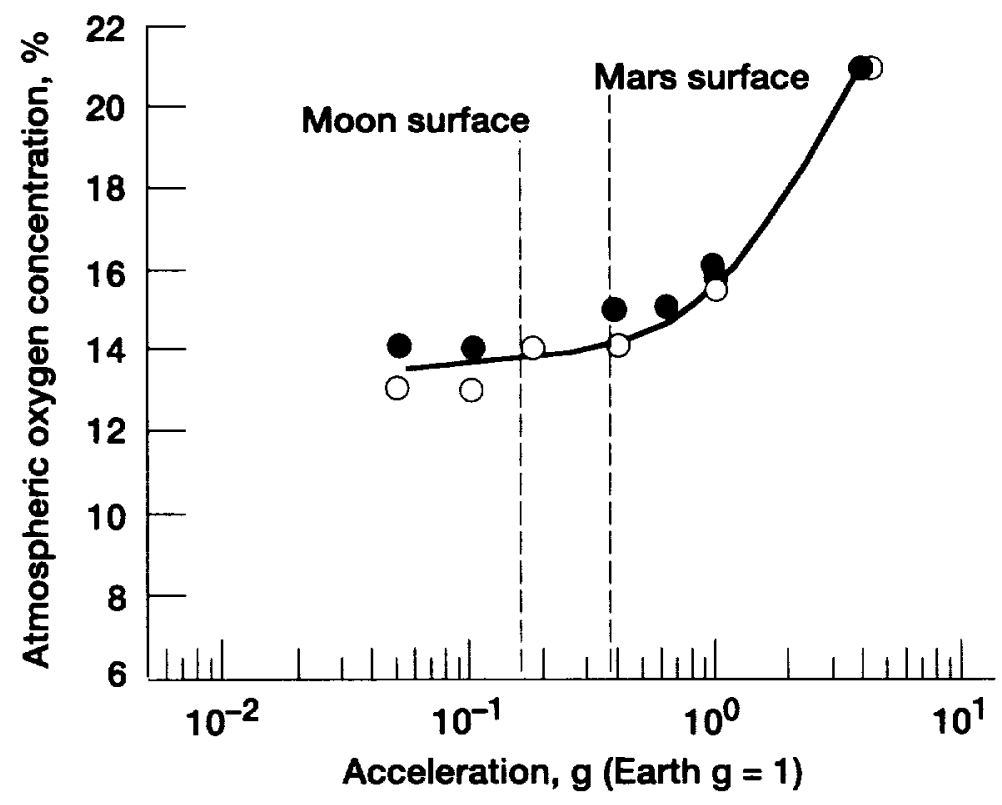

Figure 2. Experimental flammability map for downward burning thin-paper fuels at $101 \mathrm{kPa}$ total pressure. Open symbols are non-ignition points. 
As is the case for flame propagation, it is not possible to generalize, without more data, the effects of gravity on fire and smoke detection. A study aiming to resolve some of these practical difficulties was conducted on the Shuttle to examine the particulate emissions from typical, well-established pyrolysis and fire events (paper, foam rubber, and so on) and to record the responses of a Shuttle smoke detector and an ISSprototype smoke detector (Urban, et al., 1997). The investigators noted that the detector responses in normal gravity are not indicative of their responses to the same fire events in microgravity, although both detectors showed adequate, if not optimal, sensitivity in microgravity.

The influence of partial gravity on fire signatures is entirely unknown. The corresponding research on partial-gravity flammability behavior implies that smoke density, particle morphology, flame radiation, and combustion products, among others, may be unique in partial gravity and not predictable by interpolation between normal and microgravity values.

\section{Fire Suppression}

The first-order response to a fire event in spacecraft is isolation. Local power and air flow are to be turned off. These common-sense actions eliminate a possible fire source and, in microgravity, reduce flame spread.

For established or difficult fires, spacecraft carry fire extinguishers to suppress fires through cooling, oxygen exclusion, or chemical-reaction inhibition. The Shuttle has portable and remotely actuated fire extinguishers charged with Halon 1301 (bromotrifluoromethane). The manufacture of this agent, a stratospheric ozone-layer depleter, is now prohibited by international protocol, but existing high-priority suppression systems may continue its use. The fire-extinguishing agent in most of the ISS modules is to be carbon dioxide, selected to avoid the availability and cleanup difficulties of Halon 1301. Portable fire extinguishers, along with breathing masks, will be available at accessible locations in each module, but no centralized, fixed system is planned (Williams, 1996). The Russian segments of the ISS are to use water-foam extinguishers, similar to those already on Mir.

The specified spacecraft fire-suppression agents may be the best available in present designs, but all have recognized flaws. Halon 1301 is no longer manufactured, and it can yield toxic and corrosive byproducts. Carbon dioxide is relatively inefficient as a suppressant, and leakage of the agent into inhabited cabins poses a serious toxic threat. Water-foam mixtures can be difficult to apply effectively in low gravity, and excess agent contaminates spacecraft surfaces and atmospheres.

Fire suppression in space has been investigated only in small-scale experiments using atmospheric dilution, and their results indicate that the current agents are effective in suppressing early-stage fires in microgravity (Friedman and Urban, 1993). Efficient physical application and dispersion of agents in fighting established fires in microgravity has yet to be demonstrated, however. Furthermore, practical fire-suppression performance in partial-gravity environments is entirely unknown. An interesting possibility is the availability of carbon dioxide from the Martian atmosphere (table I) as a fire suppressant for surface operations.

For otherwise uncontrollable fires, a last-resort procedure is to evacuate the crew to a safe haven and then depressurize the module to extinguish the fire (Friedman, 1996). The Martian transit vehicles will likely have isolation compartments, for protection in the event of solar flares or other radiation incidents, which can support the crew during the depressurization, if such a drastic measure is necessary.

\section{Post-Fire Cleanup}

Even after a fire is extinguished, the immediate well-being of the mission is threatened through structural damage, injury, and atmospheric contamination. In addition, subtle long-term effects of toxic products, hidden damage, and corrosion must also be countered. Post-fire cleanup provisions now considered for the ISS can be applied as a first order to the extraterrestrial missions (Ross, Williams, and Sargent, 1994). For recovery after a serious fire in a lunar mission, a flyable but damaged vehicle may be returned to Earth in an emergency transit. For Martian missions, there is no immediate-return option, and all recovery operations must be performed in place, perhaps with temporary crew refuge in the isolation chamber, as already noted.

\section{OTHER ISSUES}

This paper has concentrated on fire safety as a critical issue in the protection of the extraterrestrial missions. There is also a strong need for more information on combustion in the proposed missions, both from a process and a safety viewpoint. 
In Mars surface-operations proposals, the Martian atmosphere is to be reacted with onboard stores of hydrogen and water to produce methane fuel and oxygen. This in-situ processing must be regulated by safety concerns not only for fire but also for high-temperature, high-pressure, and oxygen-handling hazards. In addition, the performance and efficiency of propulsion, fluid, and combustion processes in the partial-gravity and microgravity environments must be determined. Specifically, propulsion-performance maps for combustion of the in-situ generated fuels in partial gravity and microgravity are essential for predicting the thrust and range of surface-rover transportation and the ascent-module engines.

\section{CONCLUSION}

As noted in this paper, the important needs for future research on fire safety in lunar and Mars missions are (1) basic information on the flammability of practical materials under varied conditions of oxygen concentrations and radiant heat fluxes in partial gravity, (2) new methods for system scanning and early fault detection, (3) applied information on innovative agents and physical dispersion systems for fire suppression, and (4) combustion and propulsion performance of propellants produced from Martian resources.

\section{REFERENCES}

Dietrich, D.L., Ross, H.D., and T'ien, J.S. (1994), "Candle Flames in Weakly Buoyant and Non-Buoyant Atmospheres," Paper 94-0429, AIAA, Reno, Nev.

Friedman, R. (1992-93), "Fire Safety Practices and Needs in Human-Crew Spacecraft," J. Appl. Fire Safety, 2(3), pp. 243-259.

Friedman, R., and Urban, D.L. (1993), "Contributions of Microgravity Test Results to the Design of Spacecraft Fire-Safety Systems," Paper 93-1152, AIAA, Irvine, Cal.

Friedman, R. (1996), "Fire Safety in Spacecraft." Fire and Materials, 20, pp. 235-243.

Ku, J.C., Griffin, D.W., Greenberg, P.S., and Roma, J. (1995), "Buoyancy-Induced Differences in Soot Morphology," Comb. and Flame, 102, pp. 216-218.

Martin, C.F., and DaLee, R.C. (1993), "Spacecraft Fire Detection and Suppression (FDS) Systems: An Overview and Recommendations for Future Flights," TP-932166, SAE, Colorado Springs, Colo.

McKinnie, J.M. (1997), "Fire Response Aboard the International Space Station," TP-972334, SAE, Lake Tahoe, Nev.

Ramachandra, P.A., et al., (1995), "The Behavior of Flames Spreading Over Thin Solids in Microgravity," Comb. and Flames, 100, pp. 71-84.

Ross, H.D. (1996), "Combustion Processes and Applications in Reduced Gravity," Engineering, Construction, and Operations in Space V, Proc. Fifth Inter. Conf. on Space '96, Vol. 1, ASCE, New York, pp. 527-533.

Ross, H.D (1997), "Burning to Go: Combustion on Orbit and Mars," Invited Paper, Fall Tech. Mtg., Eastern States Sec., The Comb. Inst., Hartford, Conn., pp. 29-36.

Ross, R., Williams, T.A.J., and Sargent, D. (1994), "Post-Fire Cleanup on the Space Station," TP-941606, SAE, Friedrichshaven, Ger.

Sacksteder, K.R., and T'ien, J.S. (1993), "Downward Diffusion Flame Spread and Extinction in Variable Gravity Fields: Lunar and Martian Simulations," Paper 93-0828, AIAA, Reno, Nev.

Sacksteder, K.R., and T"ien, J.S. (1994), "Buoyant Downward Diffusion Flame Spread and Extinction in Partial Gravity Accelerations," Twenty-Fifth Symposium (International) on Combustion, The Comb. Inst., Pittsburgh, pp. 1685-1692.

Urban, D.L., Griffin, D.W., and Gard, M.Y. (1997), Detection of Smoke from Microgravity Fires," Paper 1, Tech. Meeting, Central States Sec., The Comb. Inst., Point Clear, Ala., pp. 6-11.

Walther, D.C., Fernandez-Pello, A.C., and Urban, D.L. (1997), "Smoldering Combustion Experiments in Microgravity," Fourth Inter. Microgr. Comb. Workshop, Sacksteder, K.R., ed., Cleveland, Ohio, CP-10194, NASA, pp. 369-374.

Williams, D.E. (1996), "International Space Station Environmental Control and Life Support System Phase Two Design Overview," TP-961470, SAE, Monterey, Cal.

Zubrin, R.M., and Weaver, D.B. (1995), "Practical Methods for Near-Term Human Exploration of Mars," $J$. Brit. Interplanetary Soc., 48, pp. 287-300. 



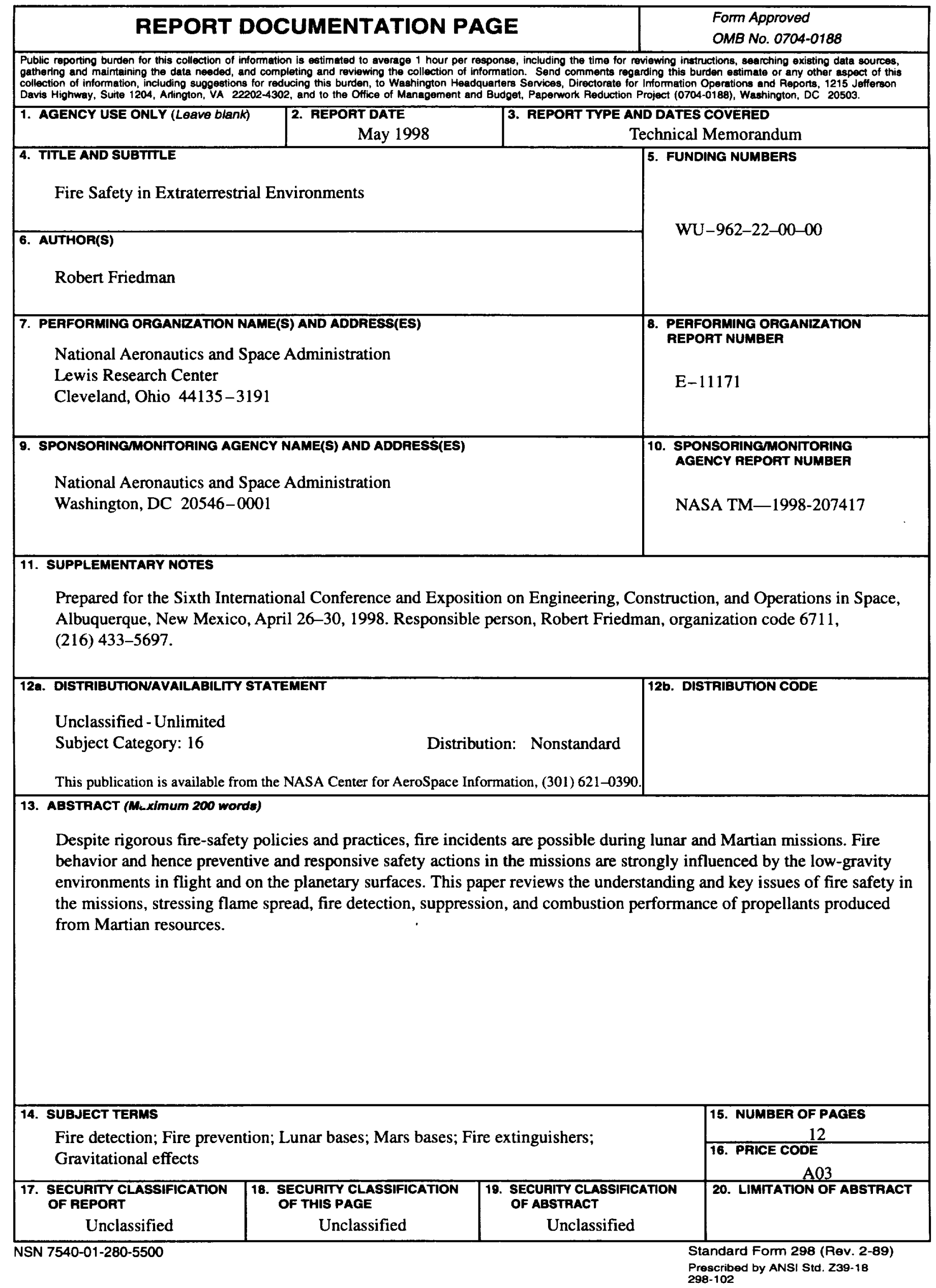

